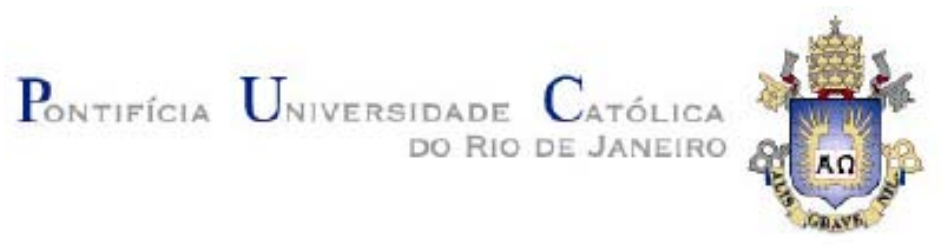

Kathia Cecília López Supo

Desenvolvimento de Permeâmetro de vazão constante de

campo

Dissertação de Mestrado

Dissertação apresentada como requisito parcial para obtenção do título de Mestre pelo Programa de PósGraduação em Engenharia Civil da PUC-Rio.

Orientador: Prof. José Tavares Araruna Júnior.

Rio de Janeiro, 07 de novembro de 2008 


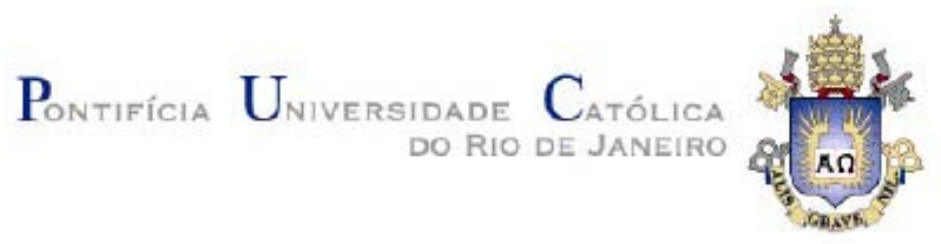

Kathia Cecília López Supo

\section{Desenvolvimento de Permeâmetro de vazão constante de \\ campo}

Dissertação apresentada como requisito parcial para obtenção do título de Mestre pelo Programa de PósGraduação em Engenharia Civil da PUC-Rio. Aprovada pela Comissão Examinadora abaixo assinada.

Prof. José Tavares Araruna Junior

Presidente/Orientador

PUC - Rio

Prof. Fernando Antonio M. Marinho

USP

Prof. George de Paula Bernardes

UNESP

Prof. Sergio Tibana

UENF

Prof. José Eugênio Leal

Coordenador Setorial do Centro Técnico Científico - PUC-Rio 
Todos os direitos reservados. É proibida a reprodução total ou parcial do trabalho sem autorização da universidade, do autor e do orientador.

\section{Kathia Cecília López Supo}

Graduou-se em Engenharia Civil, pela Universidad Ricardo Palma (Lima-Perú) em 2004. Trabalhou na área de projetos, construção e supervisão de obras de Mineração. Ingressou em 2006-II no curso de mestrado em Engenharia Civil da Pontifícia Universidade Católica de Rio de Janeiro, na área de Geotecnia, desenvolvendo dissertação de mestrado na linha de pesquisa Geotecnia Experimenta

Ficha Catalográfica

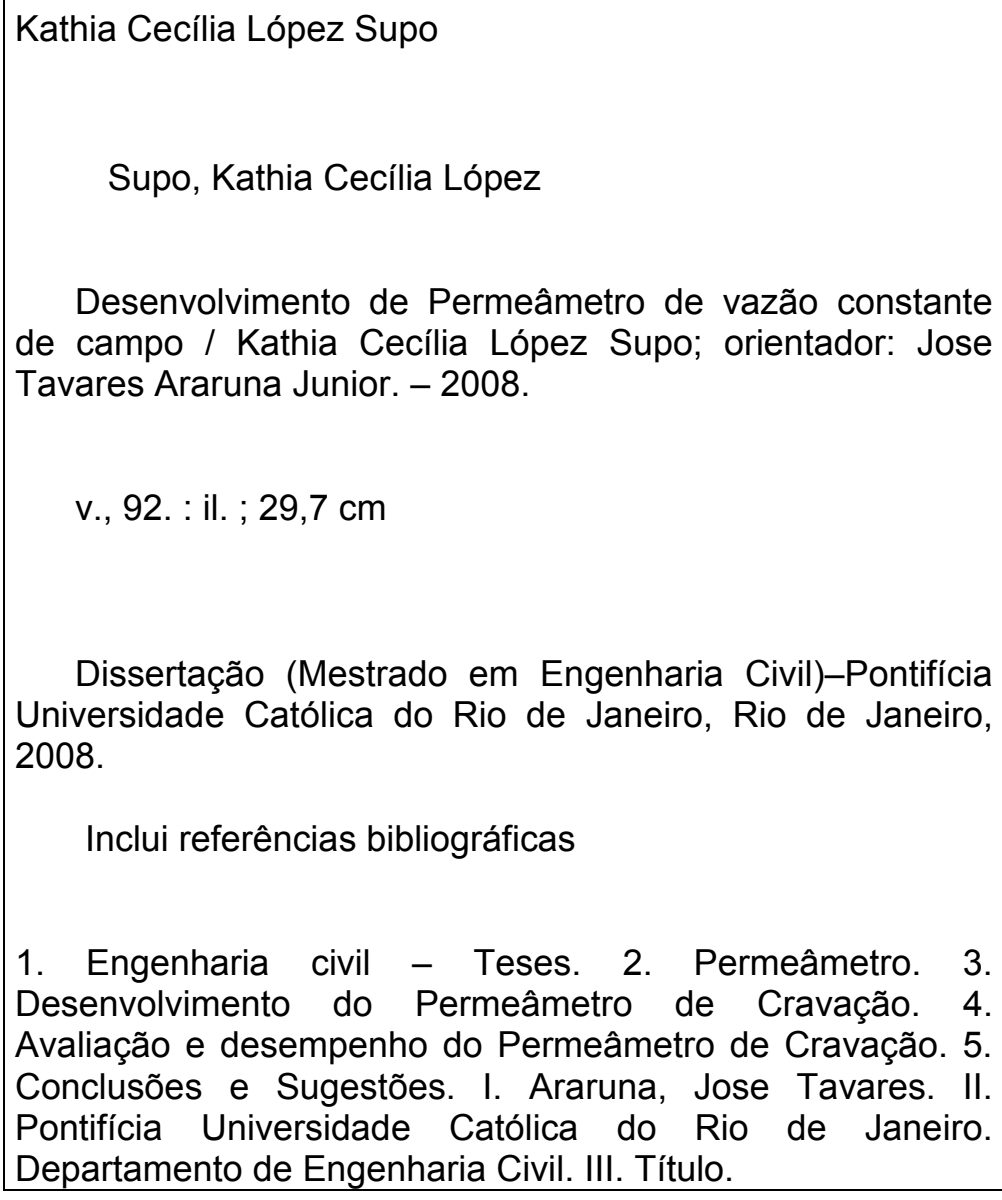

Dissertação (Mestrado em Engenharia Civil)-Pontifícia Universidade Católica do Rio de Janeiro, Rio de Janeiro, 2008.

Inclui referências bibliográficas

1. Engenharia civil - Teses. 2. Permeâmetro. 3. Desenvolvimento do Permeâmetro de Cravação. 4. Avaliação e desempenho do Permeâmetro de Cravação. 5. Conclusões e Sugestões. I. Araruna, Jose Tavares. II. Pontifícia Universidade Católica do Rio de Janeiro. Departamento de Engenharia Civil. III. Título. 
A meus queridos pais, Felipe López e Erenia Supo. Ao Emerson Figueroa por ter me dado a felicidade. 


\section{Agradecimentos}

Agradeço a Deus por estar sempre quando mais o necessite, e por todas as graças recebidas.

Ao Professor José Araruna, pela orientação, amizade e ajuda para o desenvolvimento desta pesquisa.

Ao Patrício pela amizade e a ajuda brindada em todo momento para levar a fim esta pesquisa.

Ao os meus queridos pais Felipe e Erenia pelo grande apoio, confiança e amor, graças por acreditar nos meus sonhos e pela ajuda para lograr meus objetivos.

Agradeço ao Emerson meu esposo, por tudo o apoio, compreensão e por ter sido minha fonte de inspiração e motivação.

As minhas irmãs, Angélica, Patrícia e Carolina, pelo apoio e confiança.

Aos meus queridos sobrinhos, Luciana, Oliver e Samantha

Aos meus sogros Benito e Domitila, pelo apoio e ajuda para lograr este objetivo.

Aos Professores do curso de mestrado da PUC-Rio, pelos conhecimentos transmitidos.

A todos os amigos e companheiros de estudos de Engenharia Civil da PUC-Rio, e de maneira muito especial as minhas queridas amigas Gladys, Carmen e Gricel, pelos momentos compartidos que sempre estarão guardados na minha memória.

A meus amigos David e Gustavo pelo apoio e amizade brindada durante estes anos. 
Aos funcionários do ITUC, Marquez, Braiz e Paulo pela amizade dispensada e a grande ajuda na confecção da sonda.

Aos funcionários do laboratório de Geotecnia, William, Davis e Amaury, pela ajuda e assistência dispensada.

À CAPES pela ajuda financeira indispensável ao desenvolvimento deste trabalho. 


\section{Resumo}

Kathia Cecília López Supo, José Tavares Araruna Junior. Desenvolvimento de Permeâmetro de vazão constante de campo. Rio de Janeiro, 2008. 92p. Dissertação de Mestrado - Departamento de Engenharia Civil, Pontifícia Universidade Católica do Rio de Janeiro.

A presente dissertação descreve o desenvolvimento de um equipamento destinado a determinar a condutividade hidráulica de meios porosos saturados in situ. O permeâmetro consiste em uma sonda que emprega o método da vazão constante. Após sua inserção pelo modo de cravação. Uma bomba de seringa instalada na superfície do terreno é utilizada para aplicar uma vazão constante enquanto que a carga hidráulica induzida no meio é medida através de um transdutor de pressão piezoresistivo instalado no corpo da sonda. $\mathrm{O}$ equipamento permite o escoamento das linhas de drenagem e de medição de carga hidráulica a partir da superfície possibilitando a saturação do meio poroso após a cravação da sonda bem como minimiza as incertezas associadas à medição de pressão. Esta última é alcançada através de um transdutor diferencial de pressão com uma faixa de trabalho de $10 \mathrm{kPa}$ que possibilita medições de poropressões bem próximas a zona de injeção. Esta característica permite a realização de ensaios num tempo curto e minimiza o problema de compatibilidade de fluidos decorrente do processo de injeção.

\section{Palavras-chave}

Permeâmetro, condutividade hidráulica. 


\section{Abstract}

Kathia Cecília López Supo, José Tavares Araruna Junior. Development of a constant rate of flow field permeameter. Rio de Janeiro, 2008. 92p. M.Sc. Dissertation - Department of Civil Engineering, Pontifícia Universidade Católica do Rio de Janeiro.

This thesis describes a piece of equipment developed to determine the hydraulic conductivity of saturated porous media. The permeameter consists of a pushed in probe and employs the constant flow rate method. A syringe pump installed on the surface is used to develop a constant rate of flow whereas a piezoelectric transducer installed in the probe's body measures the induced change in hydraulic head. The great innovation in this device consists on its ability of saturating all of its drainage lines allowing the media to be saturated and minimizing the errors of pressure measurements. Pressure measurement is carried out using a $10 \mathrm{kPa}$ differential pressure transducer that enables porepressure to be measured close to the injection zone. This characteristic enables shorter tests to be carried out and minimize problems associated to fluid compability

\section{keywords}

Permeameter, hydraulic conductivity. 


\section{Sumário}

1 Introdução

2 Permeâmetro

19

2.1. Tipo de Permeâmetro 19

2.1.1. Permeâmetro de Guelph 19

2.1.1.1. Descrição do ensaio com o Permeâmetro de Guelph 20

2.1.2. Ensaio de Lefranc 23

2.1.3. Slug Test 26

2.1.3.1. Descrição do Slug Test 26

2.1.3.1.1. Método de Hvorslev 31

2.1.3.1.2. Método de Bouwer e Rice 33

2.2. Equipamentos cravados 36

2.2.1. Piezocone 36

2.2.2. Permeâmetro Cravado (DPP) 44

2.2.2.1. Considerações sobre o Emprego do Permeâmetro Cravado

3 Desenvolvimento do Permeâmetro

3.1. Características do material de confecção

3.1.1. Aço Inox 49

3.2. Projeto do permeâmetro 50

3.3. construção do permeâmetro

3.4. Detalhes das peças constituintes 56

3.4.1. Ponta cônica 56

3.4.2. Portas de Drenagem 57

3.4.3. Base do Permeâmetro 58

3.4.4. Placas Porosas 60

3.5. Dispositivos de medição empregados 62

3.5.1. Sensor de Pressão 62

3.5.1.1. Cabos elétricos e convenção de cores 
3.5.2. Calibração do transdutor Diferencial 64

3.5.3. Bomba de injeção 66

3.5.4. Calibração do Transdutor de Deslocamento 67

3.6. Aquisição de sinais 68

4 Avaliação do Desempenho do Permeâmetro Cravado 69

4.1. Procedimento do ensaio 69

4.2. Programa Experimental $\quad 71$

4.2.1. Ensaios de laboratório $\quad 72$

4.2.1.1. Resultados dos ensaios de laboratório 72

4.2.2. Ensaios no campo experimental II PUC-RIO 75

4.2.2.1. Resultados dos ensaios realizados no campo experimental 75

5 Conclusões $\quad 79$

$\begin{array}{ll}6 \text { Sugestões } & 81\end{array}$

7 Referências Bibliográficas $\quad 83$ 


\section{Lista de figures}

Figura 2.1- Permeâmetro de Guelph sendo empregado em um estudo hidrogeológico em Santos Dumont (MG) 20

Figura 2.2- Esquema do Ensaio de Lefranc (Puertos del Estado,1994) 23

Figura 2.3- Proposta de dispositivo de Custodio (1983) 25

Figura 2.4- Detalhe de um ensaio slug test realizado em uma campanha hidrogeológica em São Paulo 26

Figura 2.5- Slug Test, Weight e Wittman 27

Figura 2.6- Slug In, subida inicial e medidas de descensos da água Navfac, 1981.

Figura 2.7- Slug Out, descenso inicial e medidas de subidas da água (Navfac, 1981).

Figura 2.8 - Método pneumático proposto por McLane et al. (apud, Butler 2007)

Figura 2.9- Poço e Piezômetro, Método de Hvorlev (1949)

Figura 2.10- Esquema do ensaio de slug test, método de Bouwer e Rice (1967)

Figura 2.11- Parâmetros adimensionais A, B, C, Bouwer

Figura 2.12- Cargas numa perfuração como uma função de forma do tempo da reta de melhor ajuste durante a parte inicial do teste, mas eventualmente devidamente frente à reta ajusta. Bouwer

Figura 2.13- Desenho esquemático de CPTU (Davies e Campanella, 1995)

Figura 2.14 - Sistema de cravação

Figura 2.15- Sistema de cravação montando em um caminhão

Figura 2.16 - Aquisição automática dos parâmetros de interesse

Figura 2.17 - Piezocone com medição de poropressão na posição U2 41

Figura 2.18 Gráfico de dissipação de poropressões segundo a posição da pedra porosa, P.W.Mayne, 2002. 
Figura 2.20- Representação esquemática do permeâmetro cravado (Dietrich et al., 2007)

Figura 2.21 - Gráfico típico de um ensaio de vazão constante (Butler et al.,2007)

Figura 3.1 - Permeâmetro da Geoprobe Systems

Figura 3.2 Detalhe da posição do transdutor 50

Figura 3.3 Dimensões do Permeâmetro de cravação 52

Figura 3.4 Detalhe da ponta cônica de $30^{\circ}$ do Permeâmetro de cravação. 51

Figura 3.5 Diagrama esquemático do permeâmetro de cravação

Figura 3.6 Detalhe das partes constituintes do Permeâmetro de cravação52

Figura 3.7 Detalhe da perfuração do furo longitudinal para dar acesso a transdutor de pressões

Figura 3.8 Detalhe do furo onde é colocado o transdutor diferencial $\quad 53$

Figura 3.9 Perfuração do anel complementar

Figura 3.10 Perfuração do anel complementar

Figura 3.11 detalhe da placa porosa posição 9

Figura 3.12 Detalhe dos parafusos e do furo para a passagem dos fios do transdutor

Figura 3.13 Permeâmetro confeccionado com aço 316

Figura 3.14 Detalhe da confecção da ponta cônica

Figura 3.15 Detalhe da confecção da rosca da ponta cônica 56

Figura 3.16 Detalhe da rosca e da ponta cônica

Figura 3.17 Detalhe da porta de drenagem de $\varnothing 4 \times 3 \mathrm{~mm}$

Figura 3.18 Detalhe da porta de drenagem de $\varnothing 4 \times 3 \mathrm{~mm}$ contendo a malha no interior.

Figura 3.19 Detalhe da malha de $0.425 \times 0.425 \mathrm{~mm}$.

Figura 3.20 Detalhe dos parafusos empregados para as entradas de água59

Figura 3.21 Detalhe do torneamento dos furos para a localização dos parafusos.

Figura 3.22 Detalhe dos furos para a localização dos parafusos e canais de água.

Figura 3.23 Detalhe a luva confeccionada.

Figura 3.24 Detalhes dos diâmetros das placas porosas localizadas nas posições 1,2,3. 
Figura 3.25 Detalhes da localização da pedra porosa na posição 161

Figura 3.26 Detalhes da localização da pedra porosa na posição 261

Figura 3.27 Detalhes da localização da pedra porosa na posição 7 segunda a localização mostrada na Figura 3.5.

Figura 3.28 Transductor serie PD -10L , KELLER

Figura 3.29 Sistema interno do transdutor da serie PD-10L, KELLER

Figura 3.30 convenção de cores da montagem do transdutor diferencial (KELLER)

Figura 3.31 Cabos elétricos sendo conectados aos fios do transdutor 63

Figura 3.32 Exemplo ilustrativo dos cabos elétricos já conectados. $\quad 64$

Figura 3.33 Bomba de injeção Syringe Pumps. 66

Figura 3.34 Instrumentos utilizados para a calibração 64

Figura 3.35 Resultados da calibração do transdutor de pressão PD10L, efetuado no laboratório PUC.

Figura 3.36 montagem do parafuso micrométrico, transdutor de deslocamento e Data Logger.

Figura 3.37 Curva de Calibração do LSCT

Figura 3.38 Data Logger ALMEMO.

Figura 4.1 Localização do campo experimental II

Figura 4.2 Variação da pressão diferencial durante o ensaio realizado com a vazão de injeção de $0.000167 \mathrm{~cm} 3 / \mathrm{s}$

Figura 4.3 Variação da carga hidráulica e da injeção para o ensaio com vazão de $0.000167 \mathrm{~cm} 3 / \mathrm{s}$

Figura 4.4 Variação da pressão diferencial durante o ensaio realizado com a vazão de injeção de $0.00167 \mathrm{~cm} 3 / \mathrm{s}$

Figura 4.5 Variação da carga hidráulica e da injeção para o ensaio com a vazão de $0.00167 \mathrm{~cm} 3 / \mathrm{s}$

Figura 4.6 Variação da pressão diferencial durante o ensaio realizado com a vazão de injeção de $0,0167 \mathrm{~cm} 3 / \mathrm{s}$

Figura 4.7 Variação da carga hidráulica e da injeção para o ensaio com a vazão de $0.0167 \mathrm{~cm} 3 / \mathrm{s}$ 


\section{Lista de tabelas}

Tabela 1 Valores de a segundo o tipo de solo, Soto,(1999).

Tabela 3.1 - Parâmetros de calibração do transdutor diferencial de pressão

Tabela 4.1 Resultados dos ensaios de carga variável para a areia (SP) 72

Tabela 4.2 Resultados dos ensaios de carga variável para o material argilo - arenoso.

Tabela 4.3 Resultados dos ensaios realizados com o permeâmetro na areia

Tabela 4.4 Resultados dos ensaios realizados com o permeâmetro na areia

Tabela 4.5 Resultados dos ensaios realizados com o Permeâmetro 


\section{Lista de Símbolos}

$\mathrm{k}_{\mathrm{s}} \quad$ Condutividade hidráulica saturada

Q Vazão do regime permanente ou vazão injeitada

R razão da vazão constante obtida durante os ensaios

A área do reservatório do Permeâmetro utilizado $(36.19 \mathrm{~cm} 2)$.

H altura da carga hidráulica,

a diâmetro do orifício aberto pelo trado no solo

$\alpha \quad$ valores sugeridos respeito ao solo a ensaiar

C fator de forma, que depende da relação H/a e do tipo de solo.

$\mathrm{h}_{\mathrm{m}} \quad$ altura da água no interior da sondagem, por acima do nível freático.

L longitude da zona filtrante (m).

d. diâmetro da sondagem

$\mathrm{r}_{\mathrm{c}} \quad$ raio da tubulação $(\mathrm{cm})$

$\mathrm{R}_{\mathrm{e}} \quad$ raio efetivo do slug (cm)

t. tempo do acréscimo instantâneo inicial (s)

L comprimento do filtro

$\mathrm{k}_{\mathrm{r}} \quad$ condutividade hidráulica,

$\mathrm{r}_{\mathrm{w}} \quad$ raio do filtro,

t tempo do acréscimo instantâneo inicial (s)

$\mathrm{H}_{0} \quad$ altura de drenagem num tempo zero $\mathrm{t}=0$,

$\mathrm{H}_{\mathrm{t}} \quad$ altura de drenagem num tempo zero $\mathrm{t}=\mathrm{t}$, 


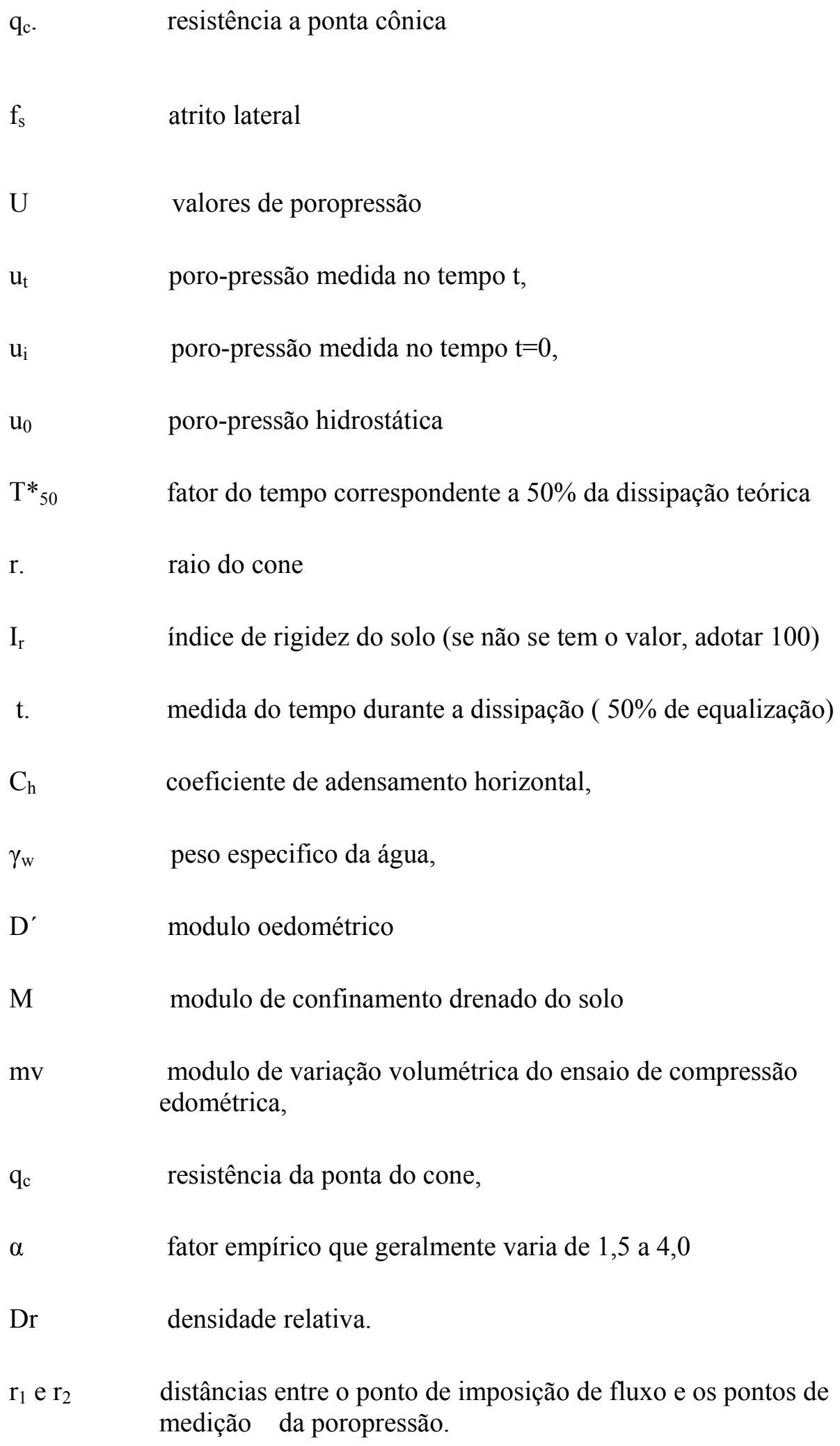

